\title{
Poisoning in children- An overview
}

\author{
Rabindran ${ }^{1}$, Verma $\mathbf{M}^{2}$ \\ ${ }^{1}$ Dr. Rabindran, Consultant Neonatologist, Billroth Hospital, Chennai; ${ }^{2}$ Mrs Mamta Verma, Associate Professor of \\ Nursing, AIIMS College of Nursing, Bhopal, MP, India.
}

Address for Correspondence: Dr Rabindran, E mail: rabindranindia@ yahoo.co.in

\begin{abstract}
Poisoning is very common problem. Clinical spectrum varies from non specific symptoms to life threatening symptoms. Toddlers are more prone for poisoning because they want to explore and taste everything.
\end{abstract}

Keywords: Childhood poisoning, gastric lavage, poisoning prevention

\section{Introduction}

Poisoning occurs when any substance interferes with normal body functions after it is swallowed, inhaled, injected or absorbed. Its spectrum varies from place to place, depending upon age, sex, socioeconomic status \& demography [1]. They are commoner among children \& are mostly accidental due to their exploratory hand-tomouth activity. Among older children intentional overdoses \& substance abuse can occur.

Common substances causing childhood poisoning include Cosmetics, Automobile fluids, Household cleaning products, Medications, Foreign objects, Paints, Pesticides, Plants, Alcohol, Corrosives, Bacterial toxins causing food poisoning like E. coli, Heavy metals \& venom found in the bites and stings of some animals and insects. Majority of poisonings may be asymptomatic with slow absorption \& delayed presentation. Common modes of presentation include Vomiting, Altered sensorium , Convulsions, Diarrhea, Urinary incontinence, Drooling of saliva, Pain \& swelling at bite site, Odour of poison, Restlessness / agitation, Fever, Hematuria, Hematemesis, Respiratory distress, Red hot skin, Headache, Blurring of vision, Anuria \& Redness of face and eyes, burns.

Children with suspected poisoning should be admitted. Serum electrolytes, renal \& hepatic function, blood glucose, ABG \& ECG should be done. Vomitus and urine samples must be examined. Plasma drug levels should be sent in suspected poisoning with drugs like acetaminophen, salicylate, iron, lithium, digoxin, theophylline, ethylene glycol, methanol, carboxyhaemoglobin, methaemoglobin, \& anticonvulsants [2].
While managing poisoned children the standard $\mathrm{ABC}$ (airway, breathing \& circulation) resuscitation approach should be followed. Caustic agents, angiotensinconverting enzyme inhibitors \& calcium oxalate may cause airway oedema and obstruction. Mental state, urine output, skin temperature \& colour should be monitored \& hypotension should be treated with bolus, judicious use of inotropes \& vasopressor support. Arrhythmias should be treated by correcting precipitating factors like hyperkalaemia, acidosis, hypoxia \& hypercarbia. Neurological function should be assessed with Glasgow coma scale \& pupillary size. Seizures should be treated using benzodiazepines; if resistant with sedation, intubation \& ventilation. Fever secondary to poisoning with sympathomimetics, salicylates, anticholinergics \& ketamine should be treated. Diuresis, vomiting, and diarrhoea may lead to profound dehydration $\&$ shock which should be treated with aggressive fluid resuscitation. In exposure to skin and mucosa, thorough washing is recommended. In exposure to fumes, management of airway burns \&respiratory support may be needed. Snake bite and bee sting must be treated aggressively with intensive monitoring.

Gastrointestinal decontamination is recommended in recent ingestion \& in symptomatic children only. Activated charcoal is safest \& reduces amount of drug absorption by adsorbing many toxins except metals, alcohols \& petroleum distillates [3]. Multiple dosing is required for drugs with entero-enteric circulation such as theophylline \& carbamazepine. Gastric lavage is contraindicated in poisonings by hydrocarbons, acids \& 
alkalis [4]. There is no role of emetics [5]. Whole-bowel irrigation with Polyethylene glycol is useful for ingestions like lead paint, iron tablets \& batteries [6]. Urinary alkalinization with sodium bicarbonate increases elimination of drugs like salicylate, isoniazid, phenobarbitone, dichlorophenoxyacetic acid \& chlorpropamide [7]. Extracorporeal therapy like Haemodialysis, charcoal haemoperfusion, plasmapheresis, exchange transfusion \& continuous ultrafiltration techniques are useful for poisonings with theophylline, lithium, salicylates, methanol, vancomycin, isopropanol poisoning \& ethylene glycol [8]. Dialysis is helpful when concomitant electrolyte or acid-base disturbance exists. Haemoperfusion is better for toxins with low water solubility \& haemofiltration removes compounds with high molecular weight.

About $1 / 3^{\text {rd }}$ of under 5 children with accidental poisoning will subsequently have a second episode. Adequate supervision, safe placement of medications and toxic chemicals with child-safe cabinets \& containers out of reach of children have a valid role in preventing accidental poisonings [9]. With the use child-resistant containers, reducing pack sizes of drugs, prompt suspicion and referral to poison centre may reduce deaths in children from poisoning [10].

Funding: Nil, Conflict of interest: None initiated, Perission from IRB: Yes

\section{References}

1. Khadgawat R, Garg P, Bansal P, Arya A, Choudhary B. Accidental Poisoning. Indian Pediatr. 1994; 31:15551557.

2. Greene SL, Dargan PI, Jones AL. Acute poisoning: understanding $90 \%$ of cases in a nutshell. Postgrad Med J. 2005 Apr;81(954):204-16.
3. Vale JA. Position statement: gastric lavage. American Academy of Clinical Toxicology; European Association of Poisons Centres and Clinical Toxicologists.J Toxicol Clin Toxicol.1997;35(7):711-9.

4. Chyka PA, Seger D. Position statement: single-dose activated charcoal. American Academy of Clinical Toxicology; European Association of Poisons Centres and Clinical Toxicologists. J Toxicol Clin Toxicol. 1997; 35(7):721-41.

5. Krenzelok EP, McGuigan M, Lheur P. Position statement: ipecac syrup. American Academy of Clinical Toxicology; European Association of Poisons Centres and Clinical Toxicologists. J Toxicol Clin Toxicol. 1997; 35(7):699-709.

6. Tenenbein M. Position statement: whole bowel irrigation. American Academy of Clinical Toxicology; European Association of Poisons Centres and Clinical Toxicologists [review]. J Toxicol Clin Toxicol. 1997; 35(7):753-62.

7. Yarbrough BE. Current management of the poisoned patient. South Med J. 1988 Jul; 81(7):892-901.

8. Bunchman TE, Valentini RP, Gardner J, Mottes T, Kudelka T, Maxvold NJ. Treatment of vancomycin overdose using high-efficiency dialysis membranes. Pediatr Nephrol. 1999 Nov;13(9):773-4.

9. Clamp M, Kendrick D. A randomised controlled trial of general practitioner safety advice for families with children under 5 years. Br Med J 1998; 316:1576-9.

10. Hawton K, Townsend E, Deeks JJ, Appleby L, Gunnell D, Bennewith $\mathrm{O}$, et al. Effects of legislation restricting pack sizes of paracetamol and salicylates on self poisoning in the United Kingdom: before and after study. BMJ2001;322:1203-7.

\section{How to cite this article?}

Rabindran, Verma M. Poisoning in children- An overview. J PediatrRes.2017;4(05):293-294.doi:10.17511/ ijpr.2017.i05.01 